\section{DIGITAL COMMONS \\ @ UNIVERSITY OF SOUTH FLORIDA}

Journal of Practitioner Research

\title{
Teaching Principals to Be Action Researchers: The Indiana Principal Leadership Institute Coaching Model
}

\author{
Nancy Fichtman Dana \\ University of Florida, ndana@coe.ufl.edu \\ Linda Marrs-Morford \\ Indiana State University, linda.marrs-morford@indstate.edu \\ Shelley Roberts \\ University of New Mexico, shelleyroberts2@earthlink.net \\ Kelly Laffoon \\ Williamsport Elementary School, klaffoon@msdwarco.k12.in.us
}

Follow this and additional works at: https://digitalcommons.usf.edu/jpr

Part of the Educational Leadership Commons, and the Elementary and Middle and Secondary

Education Administration Commons

\section{Recommended Citation}

Dana, Nancy Fichtman; Marrs-Morford, Linda; Roberts, Shelley; and Laffoon, Kelly (2017) "Teaching Principals to Be Action Researchers: The Indiana Principal Leadership Institute Coaching Model," Journal of Practitioner Research: Vol. 2 : Iss. 1 , Article 1.

http://doi.org/10.5038/2379-9951.2.1.1038

Available at: https://digitalcommons.usf.edu/jpr/vol2/iss1/1

This Conceptual Paper is brought to you for free and open access by the Open Access Journals at Digital Commons @ University of South Florida. It has been accepted for inclusion in Journal of Practitioner Research by an authorized editor of Digital Commons @ University of South Florida. For more information, please contact digitalcommons@usf.edu. 


\begin{abstract}
This article chronicles a year-long model of engagement in action research for administrators as it unfolds within a professional development program for practicing principals. Part one of the article, authored by the program developers, describes five components of the inquiry coaching model: (1) introducing the action research process, (2) developing a wondering/research question, (3) developing a plan for research, (4) analyzing data, and (5) sharing work with others. Part two of the article, authored by a principal, provides an example of action research produced by a participant in program.
\end{abstract}

Grounded in the work of John Dewey (1933), the process of action research has long served as a powerful tool to help teachers better understand and improve their work. According to Glanz (2005), "Although it was developed primarily for the professional development of teachers, action research has recently gained favor among principals as a way of improving schools by focusing on reflective practice for instructional improvement" (p. 18). As such, the process has been adopted as a signature pedagogy for school leader preparation programs in order to allow graduate students studying the principalship "to explore the empirical realities of their workplace and to reflect on these realities in light of current trends in the field and exemplary practices reported in the literature" (Sappington, Baker, Gardner, \& Pacha, 2010, p. 252 253). In addition, it has been used by university faculty teaching in educational leadership programs to examine the content and outcomes of university-based principal preparation programs to inform continuous program improvement (Carver \& Klein, 2013).

Mitgang and Gill (2012) assert, "Getting pre-service principal training right is essential. But equally important is the training and support school leadership receive after they're hired" (p. 20). While a good deal of work has focused on the infusion of action research into the initial preparation of principals (Darling-Hammond, LaPointe, Meyerson, Orr \& Cohen, 2007), practicing principals also benefit from engagement in action research as a mechanism for the continuation of their own professional learning (Dana, Tricarico \& Quinn, 2010). Yet, once principals graduate from the university educational leadership programs that prepare them, it is challenging to create structures to teach principals about the process of action research and to support them in its use to study their own administrative practice.

The purpose of this article is to share one structure that has been developed and enacted for this purpose - The Indiana Principal Leadership Institute (IPLI), taking the reader step by step through five critical junctures in learning to do action research and the ways IPLI addresses these critical junctures with practicing principals over the course of an entire school year. Critical junctures are defined as times in the action research process when the coaching a 
principal researcher receives is critical to the ultimate outcome and quality of the action research endeavor (Dana \& Yendol-Hoppey, 2008). While still in its infancy, the model we present has shown promise in creating powerful professional development for practicing principals through engagement in action research (Dana, Marrs-Morford, \& Roberts, 2015).

\section{The Indiana Principal Leadership Institute}

Recognizing the increased challenges facing today's principals, the Indiana Legislature created the Indiana Principal Leadership Institute (IPLI) in 2013. The two-year, intensive professional development program provides "building-level principals with the skills and tools needed to increase their personal leadership capacities, as well as to increase the learning capacities of their schools" (http://www.indianapli.org/). Each year, approximately 50 practicing principals, nominated by district-level supervisors, are selected to participate in the institute, divided into regional focus-cohort groups, and assigned a trained mentor.

The institute has several components that contribute to an overall program that focuses on reflection, growth, and renewal. Each year principals are engaged in:

- A two-day, whole-group summer institute;

- Four whole-group, day-long seminars during the school year;

- Monthly regional focus-cohort meetings;

- One-on-one mentoring; and

- Action research.

Principals also receive membership, conference registration, and access to resources with the Indiana Association of School Principals.

The design of the IPLI experience is based on the large body of research indicating the significant impact a principal has on student achievement in schools (Marzano, Waters, \& McNulty, 2005; The Wallace Foundation, 2013). Therefore, in year one, the focus is on increasing the leadership capacity of the principal. Principals collect data from their staffs about their leadership skills and the culture of their schools. With this information, principals identify key leadership skills to address. IPLI utilizes an action research process to help participants understand how to use a research-based approach for improvement. It is clearly evident, based on program exit survey data, that the key to the success of the program has been the use of mentors to support principals during their IPLI action research journey.

The biggest component of the IPLI mentor's work is coaching the personal action research of the principals in their five to six-member regional 
cohort groups. As research on the coaching of action research reveals, "individuals who serve in a coaching role could benefit from the development of a structure to support their efforts and their positions as coaches" (Krell \& Dana, 2012, p. 837). The IPLI structure of alternating whole group seminars and monthly meetings with regional cohort groups throughout the calendar year focuses the mentors and their regional cohort members on five critical junctures in learning how to be an action researcher.

Prior to the start of IPLI, mentors receive eight hours of training about how to teach and facilitate their principals through the critical junctures. Mentors are given Leading with Passion and Knowledge: The Principal as Action Researcher (Dana, 2009) to read with their principals that guides the process of action research step by step and a book on coaching the action research process (Dana \& Yendol-Hoppey, 2008). Mentors receive a monthly newsletter with suggested meeting plans for each critical juncture. In addition, mentors meet the day before each seminar for additional training and the opportunity to engage in discussions about each critical juncture.

\section{Critical Junctures in the Action Research Process}

The five critical junctures in the action research process where coaching is essential are: (1) introducing the action research process, (2) developing a wondering/research question, (3) developing a plan for research, (4) analyzing data, and (5) sharing work with others (Dana \& Yendol-Hoppey, 2008). The next sections will review each of these critical junctures, explain why they are important, and describe how they are addressed in the IPLI action research coaching model.

\section{Introducing the Action Research Process}

While the process of action research has been around for ages (Adelman, 1993), there are many principals who are still not familiar with the process or have misconceptions about what the process entails and the ways it differs from traditional university research. Because the demands on a principal in the workplace can be overwhelming (Copland, 2001), they often meet the invitation to engage in action research as a powerful mechanism for their own professional learning with a fair amount of skepticism. For these reasons, the introduction principals receive to the action research cycle is the first critical juncture in the coaching process.

The introduction principals receive must provide a solid overview of the process, help principals unpack their prior conceptions of educational research, and explore the ways action research differs from large-scale educational research. It must both excite principals about the possibilities inherent in studying their own 
administrative practice and schools while assuring principals they are capable of seamlessly integrating the act of research into their everyday practice and administrator lives.

To achieve these goals, the first step in the IPLI principal action research coaching model entails an extensive action research kick-off at the first IPLI seminar that takes place on the Indiana State University campus for two days in July. During this session, principals have the opportunity to voice the images that come into their minds when they hear the word "research." Principals, in general, are not overly enthused by these images (i.e., "long hours in the library," "writing a dissertation," "crunching numbers") and do not see how these images fit with the realities of their daily lived experiences leading their schools. Hence, a good deal of time is spent deconstructing these images to show the ways they are antithetical to the process of action research. This is accomplished through sharing extensive examples of action research completed by teachers and principals both locally and across the nation.

To excite principals about the possibilities inherent in studying their own administrative practice and schools, on the second day of the institute, principals from the previous cohort present their action research in a conference-like format. At this sharing session, the new first-year IPLI principals can choose two specific examples of action research to learn about that were completed within the IPLI professional development program the previous year.

Finally, during day two of the institute, the principals are introduced to the IPLI action research mini-cycle, designed to help the principals develop an initial "feel" for the process and the meaning it could have for their practice by investing just a small amount of time between the July Institute and September Seminar. The IPLI action research mini-cycle consists of five options, each requiring just $60-90$ minutes of a principal's time prior to the next whole-group seminar in September. The topics cover the value of Twitter, webinars, and literature for a principal's practice, as well as time and stress management (Figure 1).

At the August regional cohort group meeting, mentors check in with their principals on option choices and progress made to date. At the whole-group September seminar, principals are led through a data analysis exercise and provided the opportunity to summarize and share their mini-cycle learning with others both within and outside of their own regional cohort group. Through this mini-introduction to action research, principals "get hooked" on the process through experiencing it in a very manageable way, and are ready to begin a personal action research cycle. 


\title{
Figure 1: Sample Action Research Mini-cycle Options
}

\begin{abstract}
Drilling Deep into an Important Educational Topic through Literature. Select a topic that is of importance to you as a principal (perhaps something you want to learn more about from the Summer seminar you just experienced) and read 3-5 articles on that topic from such journals as Educational Leadership, Phi Delta Kappan, Journal of Staff Development, Principal Leadership, and/or Principal Magazine. (Your mentor and/or IPLI staff can help you locate articles on your topic of interest). Take notes on each article that provide a brief summary/overview of the piece, and include your reflection on the prompt: "What is the most important/interesting thing I learned about my topic of interest through reading this piece and what impact, if any, will it have on my administrative practice?" These notes become your "data" to answer the question "How can the reading of literature on an important topic to me inform my administrative practice?" Bring your notes with you to our September seminar and be ready to "analyze" this data and share the articles you read and what you learned as a result with your cohort members.
\end{abstract}

Time Management and the Principal. Take a look at the months of October and March of your calendar from the previous school year. Using the following key: "M," "I," "P," "O," code these two months of your calendar as follows:

M - Management - actions that relate to the management of the facility (school building) as well as the people within (student supervision, student discipline, employee supervision, scheduling, etc.)

I - Instruction - actions that relate directly to teaching and learning of the adults and students in your school (work with students, observations/walk-throughs, teaching/modeling, professional development, planning and curriculum assessment, feedback)

P - Personal - lunch, breaks, restroom, errands, personal business

O - Other

(adapted from National SAM Interaction Project): http://www.samsconnect.com)

These two months of your coded calendar become your "data" to answer the question "How am I currently using my time and how might I better use my time as a principal?" Bring your coded calendar with you to our September seminar and be ready to "analyze" this data and share your calendar and what you learned as a result of coding it with your cohort members.

To achieve this goal, the second step in the IPLI principal action research coaching model begins at the September whole-group seminar. Each principal receives the results from a self-assessment of their personal leadership capacity, a non-evaluative staff survey that rated their performance based on the national standards for principals, and a self-assessment about their growth mindset. An explanation of how to interpret the results for each assessment is provided. Mentors lead their principals in an analysis of the data, identifying strengths and areas for potential growth.

Between the September Seminar and the October regional cohort meeting, principals are encouraged to review their data. In addition, principals are given a reading assignment describing nine passions an administrator might hold about practice to trigger action research question development (Dana, 2009). At the October regional cohort meeting, mentors facilitate a discussion about the 
passions and subsequently lead their principals through a brainstorming exercise to identify questions they have about their practice related to each passion. Next, principals place stars by their top three wonderings and share these with the group for discussion. After all have shared, each principal is asked to circle the wondering he/she wishes to explore and works on further refining that question with the help of their mentor and regional cohort group members.

\section{Developing a Plan for Research}

Once the process of action research is ignited with the birth of a wondering, a crucial next step is the development of a research plan. In the absence of a well-developed plan for action research, principals "risk making little or no progress in their work, getting lost, or even returning to the comfort of the ways their (administrative practice) has always been done without the benefits and insights that inquiry can bring" (Dana, 2008, p. 95-96). For this reason, the third critical juncture principals face is articulating a doable plan for their research that will provide a roadmap for their inquiry journey.

The development of a road map may take the form of an "inquiry brief," defined by Hubbard and Power (1999) as "a detailed outline completed before the research study begins" (p. 47). In general, a research brief is a one to two-page summary that covers such aspects as the purpose of the study, a statement of the wondering(s), a plan for how the principal will collect and analyze data, and a timeline for the study to unfold (Dana, 2009). Through the process of developing a brief, principals commit their energies to one idea and develop a sense of direction. Just as it takes time and play for principals to articulate their wonderings, it takes time and playing with each component of the inquiry brief for principals to design a solid plan of attack for their research.

To achieve this goal, the third step in the IPLI principal action research coaching model entails a two-hour regional cohort meeting within the November seminar. Each principal is asked to develop a 1-2 page draft inquiry plan. Principals come to this meeting with enough copies of their inquiry plan for each member of their regional cohort. Mentors use a protocol, defined as "a script or series of timed steps for how a conversation among (principals) on a chosen topic will develop" (Dana \& Yendol-Hoppey, 2016), to provide the opportunity for everyone to both give and receive feedback (Figure 2).

After the November meeting, mentors work with principals to finalize their inquiry plans. Principals begin implementation of their plans in December and start collecting data. 
Figure 2. Inquiry Brief Discussion Protocol

Suggested Group Size: 3 - 4

Suggested Time Frame: 15 - 20 MINUTES PER GROUP MEMBER

1. Select a timekeeper.

2. Presenter hands out a hard copy of the inquiry brief to each member of the group.

3. Group members silently read the inquiry brief, making notes of issues/questions they might like to raise in discussion with presenter (4 minutes). As group members read the brief, presenter engages in a writing activity to complete the following sentences:

Something I would like help with on my inquiry brief is ... One thing this group needs to know about me or my proposed inquiry to better prepare them to assist me is ...

4. At the end of four minutes (or when it is clear that every member of the group has completed reading and taking notes on the inquiry brief, and the presenter has finished his/her response to the writing activity), the timekeeper invites the presenter to read his/her sentence completion activity out-loud. (No more than one minute).

5. Participants talk to each other as if the presenter was not in the room, while the presenter remains silent and takes notes. (Approximately 10 Minutes) Participants focus on each of the following:

- Provide "warm feedback" on the inquiry brief. This is feedback that is positive in nature and identifies areas of strength. (1-2 minutes)

- Address the Area the Presenter Would Like Help On and Discuss the Following Questions ( 8 - 10 minutes):

A. What match seems to exist (or not exist) between the proposed data collection plan and inquiry question?

B. Are there additional types of data that would give the participants insights into his/her question?

6. Time keeper asks the presenter to summarize the key points made during the discussion that he/she wishes to consider in refining his/her plan for inquiry (1 minute). 


\section{Analyzing Data}

After fine-tuning plans for inquiry based on feedback and collecting data as articulated in this plan for a period of time, action researchers often feel overwhelmed when they get to the data analysis phase of their studies and face making sense of a huge pile of data. Hence, the fourth critical juncture in the action research process is data analysis. Principals need support to dig deep into their data to discover and articulate the learning that has occurred for them and support statements of their learning with evidence from their data.

To achieve this goal, the fourth step in the IPLI principal action research coaching model entails discussing each principal's data during the February and March regional cohort meetings. Principals prepare for these meetings by reading through their entire data set and generating three statements that reflect what they are learning from their data. They present these statements to receive feedback from all regional cohort group members utilizing a protocol similar to the inquiry brief protocol shown in Figure 2 (See Dana, 2009, p. 119-121).

\section{Sharing Work with Others}

An important way to bring closure to a cycle of inquiry for action researchers is to make their work public by sharing it with other professionals the fifth critical juncture. Not only is this important to bring closure to one action research cycle, but the process of preparing to share one's action research with others itself helps principals clarify their own thinking about their work. In addition to clarifying their own thinking, in the actual sharing of their work, principals give other administrators access to their thinking so they can question, discuss, debate, and relate. The sharing process helps principals and their colleagues push and extend thinking about practice as well, enabling a principal's colleagues to learn from the research he/she conducted.

To achieve this goal, the final step in the IPLI principal action research coaching model entails presenting at the annual IPLI Action Research Showcase. Two weeks before the April seminar, principals are asked to submit a summary form of their project:

- Project title

- Background that led to your inquiry

- Statement of wondering

- Methods/Procedures used including data collection and analysis

- What did you learn (supported with data)?

- What are your next steps?

In addition, principals are asked to provide a short project abstract. A conferencestyle program is then created (http://www.indianapli.org/wp-content/uploads/AR- 
Showcase2.pdf). During the showcase, principals present a 10-minute PowerPoint and engage in a discussion of their research with colleagues. Principals also have the opportunity to attend the sessions of others. The showcase ends with a celebration to commemorate the learning that has occurred through the principals' first full cycle of the action research process.

In year two of IPLI, the focus shifts to the school when two teacherleaders join each principal in IPLI activities to develop a plan to increase the learning capacity of their school. Action research is again used with the principals teaching and coaching their school teams through the process, assisted by their mentors. The year ends with the Showcase of Schools with teams presenting their action research projects. The two-year IPLI journey for principals culminates with a formal graduation ceremony honoring the principals and mentors.

\section{Conclusion}

IPLI's professional development touchstone is systematic and sustained action research coaching with trained mentors, release time to meet regularly, feedback at the critical junctures, and the opportunity to share. The accompanying article by Kelly Laffoon provides a first-hand analysis of the IPLI's two-year action research cycle from a principal's perspective. The ultimate goal of the IPLI is to have principals internalize the action research process and to use it as their model for life-long learning and leading change, which Kelly demonstrates.

Kelly's mentor, Principal Dan Nelson of Seeger Memorial Junior/Senior High School, played an important role coaching her action research journey. He facilitated critical juncture discussions throughout Kelly's action research journey, recognizing the unique quality of the IPLI's action research coaching model - the mutual growth opportunity produced by the mentor-mentee relationship.

I have not only seen Kelly increase her leadership capacity, but I have grown as an administrator as well. It's very rewarding being part of a collaborative cohort team working together to ensure engaging and continuous professional leadership practices.

IPLI principals and mentors like Kelly and Dan are beginning to share their action research with principals around the state through presentations at the local and state level, and via electronic media. Initial program evaluation data show that 20 of the 56 Cohort \#1 principals' schools increased their school grades under the Indiana State accountability model. While it is beyond the data we have collected so far to link participation in the IPLI action research coaching model as a contributing factor to school grade increase, principals in IPLI perceive that action research has impacted their own leadership practice as well as contributed 
to school improvement (Dana, Marrs-Morford, \& Roberts 2015). The institute will continue to study the work of its graduates and the impact of the program not only on building leadership, but on student achievement as well. Below is a description of principal action research by Kelly Laffoon.

\section{Being Coached to Use Action Research: Building Leadership Capacity Kelly Laffoon \\ Williamsport Elementary School}

As an educational leader, I often ask myself ... Where can I make the biggest impact for my students and school? It seems like a simple question until one examines more closely the endless demands placed daily on an administrator. In any given day, I have found myself supervising morning drop off, responding to a parent concern, analyzing data with teachers, monitoring lunch duty, organizing plans for an upcoming school function, addressing student discipline, conducting an evaluation, and finalizing building construction plans. This endless laundry list of demands blurs the windshield of my school vision, causing my leadership capacity to be crippled behind the wheel of a vehicle headed straight for the ditch.

As a reflective leader passionate about building stronger leadership capacity, I was driven to enroll in the two-year Indiana Principal Leadership Institute (IPLI) offered through Indiana State University. Throughout year one, the journey focused on my leadership capacity. We principals began the selfexamination process in order to identify leadership skills to enhance through the action research model. As a building leader trained to continually focus on the needs of students, staff members, parents, and stakeholders, it became a challenge for me to adjust the lens to self-examine my own capacity.

Trained mentors and regional cohort groups were formed to help guide, support, and foster networking among principals through the IPLI journey. During regional focus-cohort meetings, we built deep relationships by sharing similar concerns, brainstorming ideas, reflecting on best practices, and supporting one another through the action research process.

\section{Principal Action Research}

Have you ever traveled to the grocery store in search of a perfectly ripened, crisp apple? You take your sweet time searching for your favorite brand with skin that glistens. With much anticipation, you sink your teeth into the delicious, juicy fruit, only to stop mid-bite, left with a mushy, mouthful of rotten 
applesauce. The same is true of a leader who lacks the sense of responsibility, habit of self-reflection, and passion to continually engage in professional development. From the outside, the lack of life-long learning and leadership may not be visible, but it is just a matter of time before the rotten core affects the fruit of the school from the inside out. "Success in any profession starts with a focus on self. After all, we are the one variable that we can easily and most productively influence" (Whitaker, 2012, p. 25).

In a world where student and school accountability seems to be at an alltime high, the process of administrators examining our own practice gets pushed to the side and more urgent demands overpower. IPLI, however, challenged principals to engage in action research. Administrator action research "refers to the process of a principal engaging in a systematic, intentional study of his/her administrative practice and taking action for change based on what he/she learns as a result of the inquiry" (Dana, 2009, p. 2). As I participated in the reflective process of inquiry about my leadership, constant self-examination of my own practice became interwoven into my daily routines and interactions, creating a rippling effect throughout the culture of my school. "Inquiring professionals seek out change by reflecting on their practice . . by posing questions or 'wonderings,' collecting data to gain insight into their wonderings, analyzing the data along with reading relevant literature, making changes in practice based on new understandings developed during inquiry, and sharing findings with others" (Dana, 2009, p. 9). This process became the roadmap for my journey of principal action research.

\section{Developing a Wondering}

When I close my eyes to picture a typical school day as a principal, I see myself playing Whack-a-Mole. As problems and issues rear their ugly head, I take a mighty swing with all my energy, pounding the head of the problem into the ground ... just for an even bigger issue to resurface a few seconds later. This exertion of untamed energy leaves me tired, frustrated, irritable, and unfocused. As a leader of my school, the image of me holding a large mallet, just waiting for problems and issues to break through the foundation of my school, is not the image I want to have lingering in my head. Doing action research as a participant in IPLI helped me confront this image, as "engagement in inquiry forces you to devote sustained attention to one issue, tension, problem, or dilemma you face as an educator and, in focusing, enables you to become proactive rather than reactive to your administrative practice and your work as an educator" (Dana, 2009, p. 14). The IPLI program has taught me that by devoting sustained attention and focus on one critical area, I can make a bigger impact.

This process began with the development of my wondering, a burning question I had about my administrative practice. Through meaningful 
conversations with my IPLI mentor and my regional cohort group members, I arrived at the realization that I continually struggle with confidently engaging in critical conversations that communicate my passion and vision for my school. In my role as a change agent, I define critical conversations as the crucial daily interactions and intentional conversations that I initiate when opinions vary in order to deliberately communicate and nurture my vision for the school. Like a rudder guides a lonely ship beaten from the crashing waves of the sea, I too must first recognize incidents that could thrash the vision into unchartered waters and then use tough but essential conversations to guide us toward a shared understanding framed by a common vision. "Great principals know that effective change is up to them. With a purpose, a plan, and persistence, they can make a difference in a remarkably short time" (Whitaker, 2012, p. 60-61).

One underlying reason for struggling with critical conversations is that I taught for 13 years at the same school where I am currently the principal. Many of the critical conversations that I engage in are with the same staff members whom I respect and have built strong relationships with as colleagues and friends. Another factor that plays a key role is my limited experience as an administrator. With only three full years of administrative experience, many would say... I am still wet behind the ears! These factors are evident when a parent, staff member, or teacher steps into my office, because I feel ineffective at confidently driving the conversation and leading positive change. My regional cohort group helped me turn my struggle to engage in critical conversations into the statement of my action research wondering: How can engaging in critical conversations increase my leadership capacity to formulate change for professional growth \& student success?

\section{Action and Data Collection}

Once I established my wondering, data collection was a key step for my action research. In terms of data collection, one misconception I immediately had to dispel was the belief that principals have to crunch the numbers of high stakes testing or formative assessments to find answers to questions about our practice. Although student test scores are one piece of data that can be relevant, there are many other data sources that can be important for gaining insights into our wonderings, including: field notes, interviews, documents/artifacts, student work, digital pictures, videos, reflective journals, surveys, and literature (Dana, 2009). I learned in IPLI that using multiple sources of data and triangulating data allows the practitioner to examine a wondering through different lenses and perspectives, strengthening the validity of the action research process.

With the help of my mentor and regional cohort group members, I sketched out a roadmap for my data collection to determine how engaging in 
intentional conversations might increase my leadership capacity, drawing on four sources of data: interviews, literature, field notes, and a reflective journal.

First, I interviewed a variety of professionals who have engaged in critical conversations or are skilled in the area of leadership capacity, including several interviews with my IPLI mentor, Dan Nelson. Dan suggested initiating critical conversations with questioning strategies or sentence starters, which would allow me to guide or control the conversation while eliminating accusatory or judgmental language. A few of these sentence starters or questioning strategies included:

a. Can you talk to me about........and whether or not you feel this was successful?

b. I noticed this....can you tell me more about it?

c. I am concerned about this..... what do you think the impact of this is?

d. To increase the effectiveness here....have you considered....?

Second, I read literature related to my action research topic. Important texts included The Principal as Leader of Challenging Conversations (Ontario Principals' Council, 2011) and Having Hard Conversations (Abrams, 2009). Coupled with what I learned from the interviews I conducted, these books provided a professional toolbox for initiating and preparing interactions as a part of my action research journey. Powerful strategies and resources, including questioning checklists, frameworks, case studies, scripts, and outcome maps empowered me to speak with clarity and to address challenging situations with an effective collaborative style.

Third, in an effort to keep my focus on critical conversations and to document their frequency, I developed a tracking system enabling me to jot quick field notes when I engaged in the process. In any given day, I documented several critical conversations. After jotting a brief description of the critical conversation, I indicated with an asterisk if a follow up conversation or close monitoring was needed.

Finally, I kept a reflective journal of several conversations throughout the three-month period. I wrote detailed notes of conversations where my vision was openly heard, and I walked away feeling successful, or where I felt less successful about the conversations and took a reflective approach for the next conversation:

Today I addressed a parent concern about our instructional programming and services provided to the child. I invited the district reading coach to sit in during the meeting to provide additional feedback and support. With her support, I felt confident going into the meeting. I developed an outcome map in preparation for the meeting and started the meeting with the questioning strategy, which allowed me to start guiding the conversation. Throughout the meeting, I felt confident that we thoroughly 
outlined the instructional focus and support given. In times that I felt defensive about a comment, I took a deep breath, genuinely listened to the concern, and stayed focused to the positive vision for the school. The meeting ended on a positive note where we will reconvene to monitor the situation.

... Before the meeting with my program directors, I engaged in dialogue with my mentor to discuss strategies and best practices for a positive outcome. After seeking his guidance, I was able to prepare for the meeting, brainstorm sentence starters, and develop an outcome map. During the meeting, I was calm and at ease due to my preparations. The sentence starters allowed for a collaborative approach to become the theme for positive outcomes!

During regional cohort meetings, I shared documentation about my experiences, which allowed my mentor to ask tough questions that sustained meaningful conversations among my cohort members. Our passionate dialogue provided useful feedback that I applied directly to my ongoing action research. Throughout the data collection process of action research, I found that data must be continually gathered, reflected upon, shared, and fluidly applied to your practice to make the strongest impact.

\section{Data Analysis and Findings}

With the help of my IPLI cohort, after all of my data were collected, I used the strategy of coding to articulate my learning through this action research journey. Coding allowed me to capture the essence and meaning of my action research data, reveal underlying patterns, and apply findings toward positive outcomes. Throughout my calendar of field notes, I intently coded the critical conversations in order to disaggregate the data into more manageable categories. Listed are the coded areas on which I focused during the tracking of critical conversations:

a. S=Safety and management of the school day or building

b. I=Instruction/ Professional Development

c. $\mathrm{D}=$ Data

d. SC=Student Conversation (life skill focus or goal reaching)

e. $\mathrm{PC}=$ Parent Conversation

f. E=Encouragement (positive note to strengthen the vision) 
Below is an excerpt from my calendar, illustrating how I coded my field notes:

\begin{tabular}{|l|l|l|}
\hline $\begin{array}{l}\text { Jan. } 12 \\
\text { SC=Discussed progress } \\
\text { towards reading goal } \\
\text { with student. }\end{array}$ & $\begin{array}{l}\text { Feb. } 10 \\
\text { PC= Met with parent to } \\
\text { explain our instructional } \\
\text { programming and outline } \\
\text { services provided. }\end{array}$ & $\begin{array}{l}\text { Feb. 27 } \\
\text { I/E=Discussed } \\
\text { positives and strategies } \\
\text { from an observation } \\
\text { with a teacher. } \\
\text { I= Collaborated with }\end{array}$ \\
$\begin{array}{l}\text { PLC coach to outline } \\
\text { professional } \\
\text { development aligned to } \\
\text { our school } \\
\text { improvement. }\end{array}$ & $\begin{array}{l}\text { I =achers to identify } \\
\text { instructional focus in tier } \\
\text { groups. }\end{array}$ & $\begin{array}{l}\text { program directors to } \\
\text { brainstorm positive } \\
\text { changes to implement. }\end{array}$ \\
$\begin{array}{l}\text { I=Mesting a student teacher } \\
\text { to outline expectations } \\
\text { \& focus during } \\
\text { experience. }\end{array}$ & $\begin{array}{l}\text { S=Discussed strategies for a } \\
\text { safer drop off with the } \\
\text { crossing guard. }\end{array}$ & $\begin{array}{l}\text { E=Wrote positive note } \\
\text { to teacher about } \\
\text { strategy seen during } \\
\text { walk-thru. }\end{array}$ \\
\hline
\end{tabular}

Through the lens of coding, I gleaned a clearer sense or perspective of the time devoted to each aspect of my overall vision for the school. The data revealed that every day I engaged in at least two to three critical conversations that provided an opportunity to intentionally mold and shape all facets of the school culture towards the school's vision. My continuous focus on engaging in the action research process gave me a more confident approach to initiate critical conversations and constantly kept me tied to the vision. As Whitaker (2009) states, "Living the vision can be difficult. It sometimes requires patience and professionalism of super human lengths, but this is your job. You set the standard of excellence in the school, and everyone is watching how you handle these tedious situations" (p. 58).

\section{Sharing}

Sharing the findings of action research is probably the most rewarding step in the process. To celebrate the ending of year one of IPLI, all participating administrators were asked to share their action research projects during a final showcase. Throughout this half-day celebration, 30-minute, round-table presentations provided opportunities for IPLI participants to discuss our inquiry journeys. In sharing my action research, I gained an even deeper realization of the transformation the process had on my administrative practice. As I prepared and presented my own action research, it allowed me a chance to clarify and extend my thinking into a much deeper resonation of my profession. 
Another sharing opportunity came when I was invited to present as a keynote speaker for the kickoff of Cohort \#3 of the Indiana Principal Leadership Institute during the summer of 2015 at Indiana State University. In acceptance of the honor, I outlined an action research roadmap for the next group of practitioners embarking on the journey of action research. From that presentation, I was then asked to present my action research at the Indiana Association of School Principals Fall Professionals Conference in Indianapolis, Indiana.

I have found that action research is an ongoing process that engages selfreflection, and when truly embraced, it can transform you as a professional and be a continuous vehicle for growth throughout one's administrative career. As my role has shifted from IPLI principal to IPLI mentor this year, the most valuable advice I want to pass along to the new IPLI principals is to continually network and seek opportunities to collaborate. By embracing professional development opportunities with colleagues, the growth will not only illuminate through you, but also through your students, staff, and your entire school!

\section{Conclusion}

After engaging in the action research model and finding it so relevant, I presented the practice to the teachers in my school in an effort to help make professional development more meaningful for them. With this action research model, I have found that teachers are making efforts to shift the focus from the overwhelming daily operations of teaching to intentionally striving to keep focused on the targeted professional goals. Throughout professional development opportunities, teachers continually revisit their professional development goals.

To keep teachers connected to their professional goals, I introduced the concept of action research, linking it to peer coaching. Teachers in my school are developing a wondering about their teaching, getting support with collecting and analyzing data, and gathering feedback through a peer coaching style. Similar to the mentor I was provided with in IPLI, each teacher at my school is provided a peer coach who assists in observing new classroom strategies, in providing feedback, and in supporting an action research journey. Using the IPLI coaching model as a guide, at each of our faculty meetings this school year, we focus on a different part of the action research process. Teachers serve as peer coaches for one another as they share their progress and findings along the journey.

In this first year of adapting and applying the IPLI administrator action research coaching model to my school, I have found that there are areas that need to be adapted to better fit the staff and ever-changing school year, but staff have noted great gains towards implementing action research into our overall school improvement efforts. In their words: 
(This model) gives me the opportunity to engage in more purposeful self-reflection through the action research process. Being involved in peer coaching allows me to interact with a colleague and gather his or her unique insight into the teaching profession. The meaningful discussions that follow our observations often offer me a different perspective that leads to deeper thinking. This positively influences my professional growth.

(This model) has not only helped me organize and stay on top of my professional goal for the year, but has pushed me to collaborate with colleagues throughout our building and develop a stronger understanding of the expectations of students throughout all grade levels.

Up to this point, I owe all the credit to my passionate staff, who all positively engage in professional development and always put students first. With staff feedback, our school's action research/peer coaching model will continue to be interwoven into the fabric of our school improvement and will be reflective of our collective vision. "Leading change can be a daunting task, but the best school leaders understand how to navigate the change dynamic so that all students can have the outstanding school they deserve" (Whitaker, 2012, p. $63)$. 


\section{References}

Abrams, J. B. (2009). Having hard conversations. California: Corwin.

Adelman, C. (1993). Kurt Lewin and the origins of action research. Educational Action Research, 1(1), 7-24.

Carver, C. L., \& Klein, C. S. (2013). Action research: A tool for promoting faculty development and continuous improvement in leadership preparation. NCPEA International Journal of Educational Leadership Preparation, 8(2), 162-177.

Copland, M. A. (2001). The myth of the superprincipal. Phi Delta Kappan, 82(7), 528-533.

Dana, N. F. (2009). Leading with passion and knowledge: The principal as action researcher. Thousand Oaks, California: Corwin Press.

Dana, N. F., Marrs-Morford, L., \& Roberts, S. (2015). The promise of action research: Lessons learned from the Indiana Principal Leadership Institute. LEARNing Landscapes, 9(1), 59-79.

Dana, N. F., Tricarico, K., \& Quinn, D. (2010). The administrator as action researcher: A case study of five principals and their engagement in systematic, intentional study of their own practice. Journal of School Leadership, 19(3), 232-265.

Dana, N. F., \& Yendol-Hoppey, D. (2008). The reflective educator's guide to professional development: Coaching inquiry-oriented learning communities. Thousand Oaks, CA: Corwin Press.

Dana, N. F., \& Yendol-Hoppey, D. (2016). The PLC book. Thousand Oaks, CA: Corwin Press.

Darling-Hammond, L., LaPointe, M., Meyerson, D., Orr. M. T., \& Cohen, C. (2007). Preparing school leaders for a changing world: Lessons from exemplary leadership development programs. Stanford, CA: Stanford University, Stanford Educational Leadership Institute.

Dewey, J. (1933). Democracy and education. New York: The Free Company.

Glanz, J. (2005). Action research as instructional supervision: Suggestions for principals. NASSP Bulletin, 89(643), 17-27. 
Hubbard, R. S., \& Power, B. M. (1999). Living the questions: A guide for teacher researchers. York, ME: Stenhouse.

Krell, D. E., \& Dana, N. F. (2012). Facilitating action research: A study of coaches, their experiences, and their reflections on leading teachers in the process of practitioner inquiry. Professional Development in Education, $38(5), 827-844$.

Lumpa, D., Whitaker, B., \& Whitaker, T. (2009). Motivating and inspiring teachers: The educational leader's guide for building staff morale $\left(2^{\text {nd }}\right.$ ed.). Larchmont, NY: Eye on Education.

Marzano,R. J., Waters, T., \& McNulty, B.A. (2005). School leadership that works. Alexandria, Virginia: ASCD.

Mitgang, L., \& Gill, J. (2012). The making of the principal: Five lessons in leadership training. Retrieved from Wallace Foundation website: www.wallacefoundation.org/knowledge-center/schoolleadership/effective-principal-leadership/Documents/The-Making-of-thePrincipal-Five-Lessons-in-Leadership-Training.pdf

Ontario Principals' Council. (2011). The principal as leader of challenging conversations. Ontario: Corwin.

Sappington, N., Baker, P.J., Gardner, D., \& Pacha, J. (2010). A signature pedagogy for leadership education: Preparing principals through participatory action research. Planning and Changing, 41(3-4), 249-273.

The Wallace Foundation. (2013). The school principal as leader: Guiding schools to better teaching and learning. New York, NY: Author.

Whitaker, T. (2012). What great principal's do differently: 18 things that matter most $\left(2^{\text {nd }}\right.$ ed.). Larchmont, NY: Eye on Education. 